Article

\title{
Improved Dust Emission Reduction Factor in the ADAM2 Model Using Real-Time MODIS NDVI
}

\author{
Sang-Sam Lee *(D), Yun-Kyu Lim, Jeong Hoon Cho, Hee Choon Lee and Sang-Boom Ryoo \\ National Institute of Meteorological Sciences, 33 Seohobuk-ro, Seogwipo-si, Jeju-do 63568, Korea; \\ imyunkyu@korea.kr (Y.-K.L.); xecue@korea.kr (J.H.C.); lee.heechoon@korea.kr (H.C.L.); \\ sbryoo@korea.kr (S.-B.R.) \\ * Correspondence: sangsam.lee@korea.kr; Tel.: +82-64-780-6565
}

Received: 11 October 2019; Accepted: 11 November 2019; Published: 13 November 2019

\begin{abstract}
The Korea Meteorological Administration has employed the Asian Dust Aerosol Model 2 (ADAM2) to forecast Asian dust events since 2010, where the dust emission flux is proportional to the fourth power of the friction velocity. Currently, the dust emission reduction factor (RF) is determined by the normalized difference vegetation index (NDVI). This study aims to improve the forecasting capability of ADAM2 by developing a daily dust RF using both monthly (January 2007 to December 2016) and real-time moderate resolution imaging spectroradiometer (MODIS) NDVI data. We also developed a look-up table to transform the RF using NDVI and a system to update the RF by producing MODIS NDVI data for the last 30 days. Using these data, new RFs can be produced every day. To examine the impact of RF modification, the current (CTL) and new (EXP) RFs are compared during the period from March to May 2017. The simulations are verified by ground-based $\mathrm{PM}_{10}$ observations from China and Korea. Accordingly, root mean square errors (RMSEs) are reduced by $11.58 \%$ when RF is updated using real-time NDVI data. The results suggest that recent daily NDVI data contribute positively to the forecasting ability of ADAM2, in the dust source and downwind regions.
\end{abstract}

Keywords: Asian dust aerosol model 2; dust emission reduction factor; normalized difference vegetation index; MODIS

\section{Introduction}

In arid and semi-arid regions in East Asia, Asian dust has been emitted into the atmosphere over a long period of time. Asian dust emission is particularly high in spring, but has more recently been observed in autumn and winter as well [1]. In addition to socio-economic effects, the dust also impacts human health; causing, for example, reduced lifespans, respiratory illnesses, eye diseases, etc. [2-6]. Moreover, in recent decades, the expansion of arid regions in eastern Mongolia and Manchuria has increased the frequency of dust events in downwind regions such as Korea and Japan $[7,8]$. Therefore, it is becoming increasingly important to accurately predict dust concentrations in order to mitigate the associated hazards.

The Korea Meteorological Administration (KMA) has operated the Asian Dust Aerosol Model 2 (ADAM2) for forecasting temporal changes in Asian dust since 2010. ADAM2 has gradually been improved through various studies. For example, previous research performed data assimilation using surface $\mathrm{PM}_{10}$ data [9] and moderate resolution imaging spectroradiometer (MODIS) IR-based nighttime aerosol optical thickness data [10]), and evaluated Asian dust days using $\mathrm{PM}_{10}$ and $\mathrm{PM}_{2.5}$ [11]. However, the most significant improvement in ADAM2 from its previous version (ADAM) was parameterization of the dust emission reduction factor (RF) using the normalized difference vegetation index (NDVI) [12]. The current operational ADAM2 model contains monthly RFs produced with five years of Spot4 
NDVI data (May 2007 to April 2012). However, there are clear limitations to using past NDVI data to accurately predict current Asian dust phenomena. Previous studies have shown that time-changing surface conditions, such as NDVI, are highly associated with dust emission processes; hence, it is important to use the latest data [13-15]. Therefore, the objective of this study is to improve the dust forecasting accuracy of ADAM2 by updating the surface vegetation effect to develop a RF that is based on the most recent MODIS NDVI data. To do this, we develop a new monthly cumulative dust-rise occurrence probability function using recent monthly NDVI and Global Telecommunication System (GTS) data. We then develop a system for updating the daily RF using real-time NDVI data. This new $\mathrm{RF}$ is validated through a comparison with ground-based $\mathrm{PM}_{10}$ data from both Chinese and Korean sites.

\section{Model and Data}

\subsection{Asian Dust Aerosol Model 2 (ADAM2)}

The Asian Dust Aerosol Model 2 (ADAM2) was developed by incorporating the Asian dust algorithm $[16,17]$ into the Community Multiscale Air Quality Modeling System (CMAQ) version 4.7.1, a community atmospheric chemistry transport model [18]. In ADAM2, anthropogenic aerosols are not taken into account, only dust aerosols. The ADAM2 prediction domain covers the East Asia region centered at $126^{\circ} \mathrm{E}, 38^{\circ} \mathrm{N}$ with a $340 \times 220$ grid nest of $25 \mathrm{~km}$ resolutions and irregularly-spaced 47 sigma levels from the surface to the $100 \mathrm{hPa}$ level. The Korea Meteorological Administration (KMA)'s operational global model, the Unified Model Global Data Assimilation Prediction System [19,20], data were used to provide the model with the meteorological input data.

The basic concept of the Asian dust emission algorithm in ADAM was developed by assuming that dust emission is proportional to the fourth power of friction velocity $[16,17,21,22]$. Then, RFs using U.S. Geological Survey (USGS) vegetation categories plus surface roughness length were applied to dust emissions in source regions [16,17]. The Asian dust algorithm in ADAM2 was improved by considering the RF according to seasonal variations in vegetation using the normalized difference vegetation index (NDVI) [12]. ADAM2 calculates Asian dust emission in 11 particle size bins using the same logarithmic interval for particles measuring $0.1-3.7 \mu \mathrm{m}$ in radius $[17,23]$. The suspended particle distribution is adjusted by a weighting function according to the friction velocity based on the concept of the minimally and fully dispersed particle distribution [23]. Namely, the minimally dispersed particle distribution is determined when the friction velocity is similar to the threshold value, and the fully dispersed particle distribution when it is much greater than the threshold value. The dry deposition scheme of dust employs the inferential method [24-26], whereas the wet deposition scheme follows the diagnostic cloud model in the regional Acid Deposition Model (RADM) version 2.6 [26-28]. A detailed description of the ADAM2 model is given in [12].

\subsection{NDVI Data}

The NDVI product in the MODIS vegetation indices is defined as follows:

$$
\mathrm{NDVI}=\frac{R_{N I R}-R_{r e d}}{R_{N I R}+R_{r e d}}
$$

where $R_{\text {NIR }}$ is the reflectance in the near infrared part of the $841-876 \mathrm{~nm}$ MODIS band and $R_{\text {red }}$ is the reflectance in the red part of the 620-670 nm MODIS band [29]. To identify the impact of the new version of the surface vegetation effect on the ADAM2 model, we used the monthly MODIS/Aqua product of NDVI with a spatial resolution of $0.05^{\circ}$ over a ten-year period from 2007-2016. Monthly MODIS/Aqua NDVI data were obtained from the following website: https://e4ft101.cr.usgs.gov/MOLA/MYD13C2.006. Furthermore, in order to consider daily vegetation effects, high-resolution NDVI data with a horizontal resolution of $500 \mathrm{~m}$ were used, which were obtained from the National Meteorological Satellite Center 
of KMA between February and May 2017, whenever the MODIS/Aqua satellite passed over the Korean Peninsula.

\subsection{WMO Synoptic Data}

Three-hourly Global Telecommunication System (GTS) weather reports collected from regular World Meteorological Organization (WMO) stations in the ADAM2 domain over a ten-year period, from 2007-2016, were analyzed to identify the probability function of dust occurrence. To do so, we collected current weather data with the "blowing sand" weather code (07) as well as wind speed data. The domain of the ADAM2 is shown in Figure 1 along with the five source regions of Asian dust (i.e., Gobi, Sand, Loess, Mixed, and Tibetan regions) based on [30]. There are 280 regular reporting stations in the ADAM2 domain. Among them, there are 19 sites in the Gobi region, 54 sites in the Sand region, 59 sites in the Loess region, and 148 sites in the Mixed region. In the Tibetan region, because of a lack of comparable observation sites, it is difficult to determine the soil type; therefore, we assumed that the entire Tibetan region had a Mixed surface soil type. The weather code and wind speed data from GTS sites and NDVI observations for the four source regions of Asian dust were used to calculate the dust-rise occurrence probability function according to the NDVI.

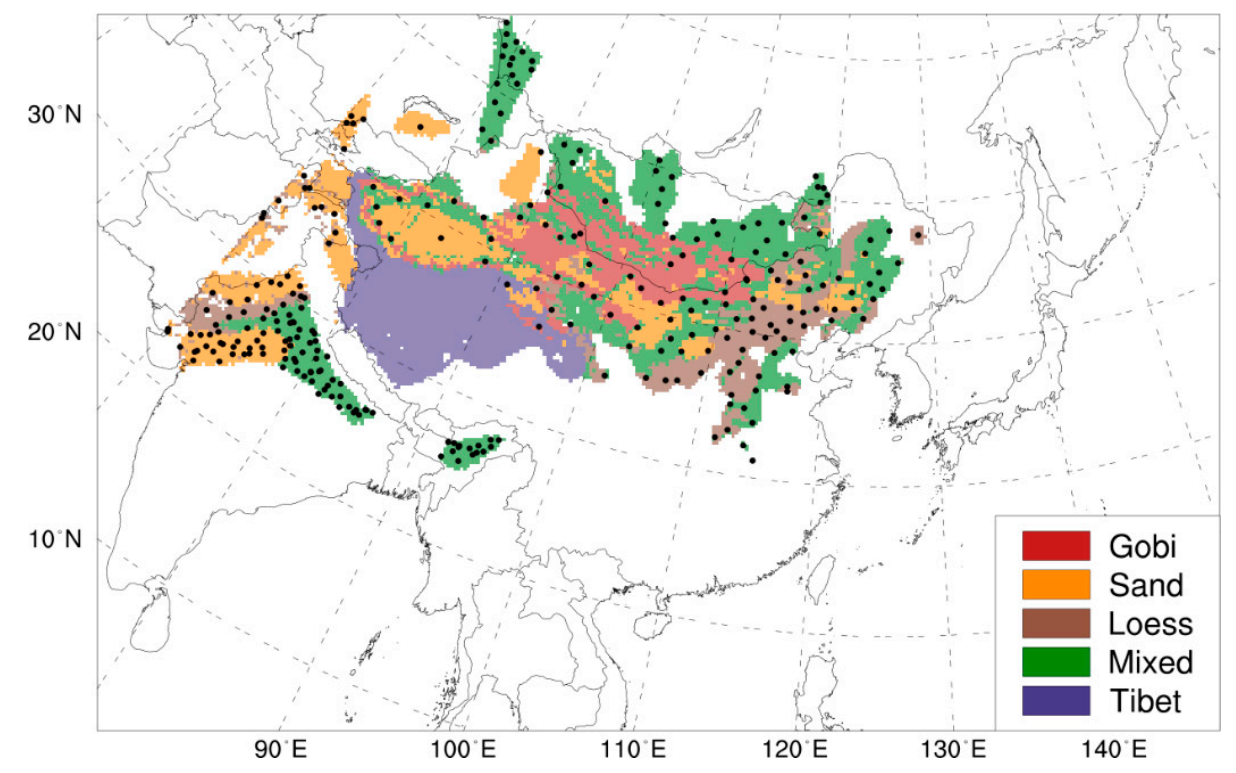

Figure 1. Spatial distribution of World Meteorological Organization synoptic stations (black circles) and surface soil types over the dust source regions for Asian Dust Aerosol Model 2 (ADAM2) (i.e., Gobi, Sand, Loess, Mixed, and Tibet).

\subsection{Surface $P M_{10}$ Data}

To validate the simulation in this study, we used the ground-based $\mathrm{PM}_{10}$ observation data from 27 KMA sites, 15 China Meteorological Administration (CMA) sites, 250 Ministry of Environment (MOE) sites in Korea, and 1498 Ministry of Ecology and Environment (MEE) sites in China.

\section{Methodology}

\subsection{New Monthly Cumulative Dust-Rise Occurrence Probability Function}

The main method in [12] was applied to calculate dust-rise occurrence frequency in Asian dust source regions. Therein, NDVI/Spot 4 and GTS data covering a nine-year period from 1998-2006 were used to identify the dust-rise occurrence probability function. In addition, a previous study has shown that the correlation between NDVI products based on MODIS and Spot is higher than that between other sensors [31]. Therefore, this study used the monthly MODIS NDVI for a ten-year period from 
January 2007 to December 2016 to reflect the more recent vegetation effect over the Asian dust source regions. Moreover, we analyzed current GTS weather code 7 data and wind speed data using monthly MODIS NDVI data. Using these NDVI and GTS data, we collected all NDVI data where the wind speed exceeded the threshold wind speed in Table 1 . Thus, the dust-rise occurrence frequency according to the NDVI value measured in intervals of 0.01 was determined for each month and surface soil type. The next step was to calculate the ratio of the dust-rise occurrence frequency to the frequency of wind speed exceeding the threshold wind speed. This ratio implies the dust-rise occurrence probability function with respect to the NDVI. Finally, the cumulative dust-rise occurrence probability function was calculated by accumulating the dust-rise occurrence probability function from a given NDVI to 1 , which indicates the probability density function of dust-rise affected by vegetation.

Table 1. Monthly threshold wind speed $\left(\mathrm{m} \mathrm{s}^{-1}\right)$ for each soil type.

\begin{tabular}{ccccc}
\hline Month & Gobi & Sand & Loess & Mixed \\
\hline 1 & 7 & 7.5 & 6 & 7.5 \\
2 & 7 & 7.5 & 6 & 7.5 \\
3 & 6.5 & 7.5 & 6 & 7.5 \\
4 & 6.5 & 6 & 5.5 & 6 \\
5 & 6 & 6 & 5 & 6 \\
6 & 6 & 6 & 5 & 6 \\
7 & 6 & 6 & - & 6 \\
8 & 6 & 6 & - & 6 \\
9 & 7 & 6 & - & 7.5 \\
10 & 7 & 6 & - & 7.5 \\
11 & 7.5 & 7.5 & 7.5 & 7.5 \\
12 & 7.5 & 7.5 & 7.5 & 7.5 \\
\hline
\end{tabular}

Figure 2 shows an example of calculating the cumulative dust-rise occurrence probability function in the Gobi soil type region in May. First, we examined the frequency distribution of wind speeds that exceeded the threshold wind speed (Figure 2a) and the dust-rise occurrence frequency (Figure 2b) in an NDVI range of 0 to 1 with an interval of 0.01 . The dust-rise occurrence probability function (Figure 2c) was then obtained by normalizing the frequency of dust-rise occurrence (Figure $2 b$ ) by dividing it by the frequency of wind speed exceeding the threshold wind speed (Figure 2a). The dust-rise occurrence frequency $(D O F(\%))$ is calculated as follows:

$$
\operatorname{DOF}(i)=100 \times \frac{f_{\text {dust }}(i)}{f_{\text {ws }}(i)} / \sum_{i=1}^{i=100} \frac{f_{\text {dust }}(i)}{f_{\text {ws }}(i)}
$$

Finally, the resulting distribution in Figure $2 \mathrm{~d}$ was normalized by dividing the total sum of the percentage distribution with respect to NDVI in Figure 2c. The cumulative dust-rise occurrence probability function $(C D F(\%))$ is calculated as follows:

$$
\operatorname{CDF}(i)=\sum_{j=i}^{j=100} D O F(j)
$$

The cumulative dust-rise occurrence probability functions (CDFs) were retrieved for every soil type and all 12 months (see Supplementary Materials). Unlike the scheme in [12], this study produced a look-up table of the cumulative dust-rise occurrence probability functions with respect to NDVI with intervals of 0.01 (Figure 2d). These cumulative dust-rise occurrence probability functions were then used to generate the new RF (RF_new), as follows:

$$
R F \_n e w=1-C D F(\%) / 100 .
$$




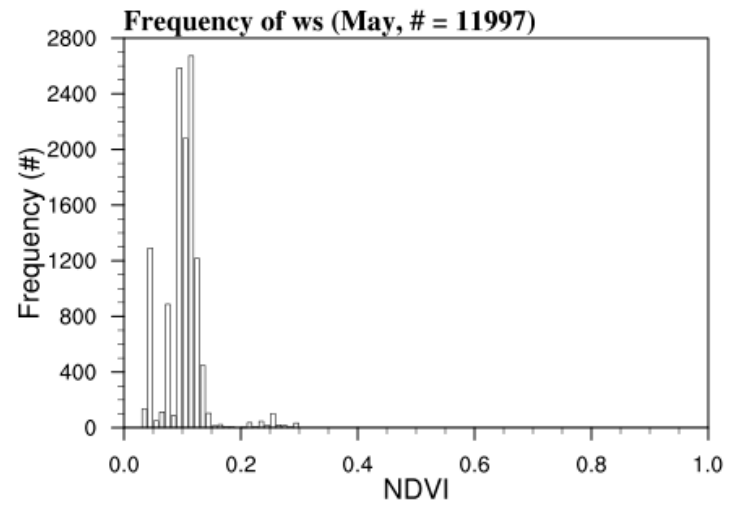

(a)

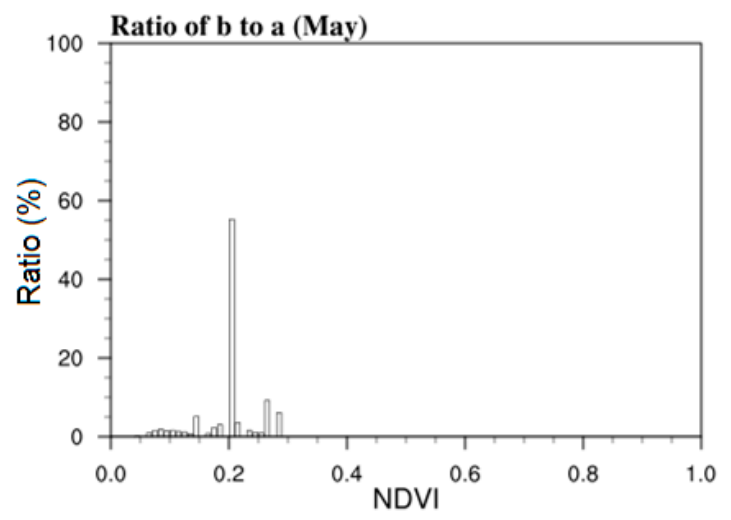

(c)

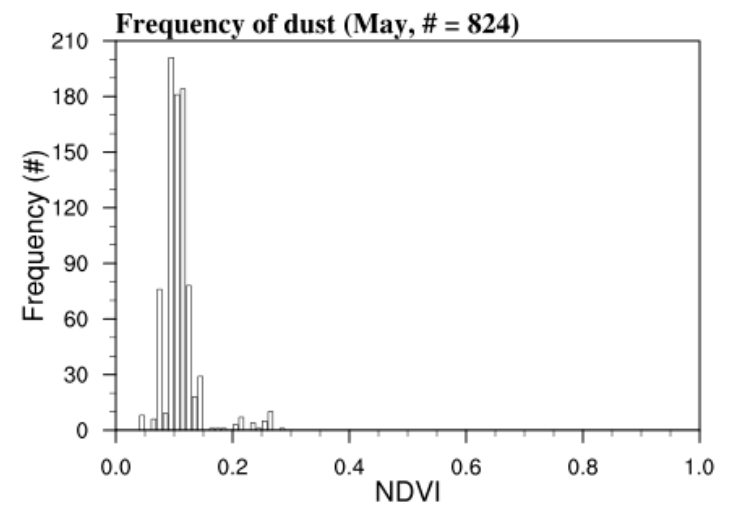

(b)

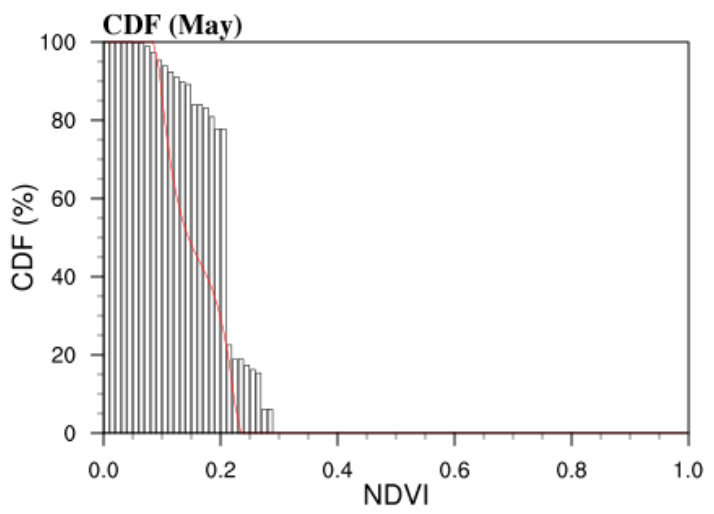

(d)

Figure 2. Occurrence frequencies of (a) wind speed exceeding the threshold wind speed and (b) dust-rise with respect to normalized difference vegetation index (NDVI) in the interval of 0.01. (c) Percentage ratio of $b$ to a. (d) Cumulative dust-rise occurrence probability function (CDF) for the Gobi soil type region in May. The red line indicates the cumulative dust-rise occurrence probability function in [12].

\subsection{Daily Reduction Factor Using Real-Time MODIS NDVI Data}

In Section 3.1, we developed the new RF based on NDVI using recent MODIS NDVI and GTS observations. In this section, we introduce a daily update system for the RF based on MODIS NDVI data for the last 30 days. The National Meteorological Satellite Center of KMA receives MODIS NDVI data with a horizontal resolution of $500 \mathrm{~m}$ when a satellite passes over the Korean peninsula. This data is used to generate high-resolution NDVI data around the Korean peninsula once a day. The procedure for creating the latest daily NDVI maps is as follows. First, the monthly average NDVI map is created by weighting the number of days in the month corresponding to 14 days in the future and 15 days in the past from the present date. The highest-resolution NDVI data are then accumulated from the past 30 days to the present day to form the most up-to-date NDVI maps. This high-resolution NDVI data is applied to the look-up-table ( Supplementary Material) and Equation (4) to produce the daily RF for the current day.

An example of generating the current daily RF is depicted in Figure 3 (May 1, 2017). In the existing version of ADAM2, the monthly NDVI data for May is used throughout May. Therefore, for the example of 1 May 2017, the May RF generated from Spot4 NDVI during 2007-2012 was used to compare the existing RF with the proposed RF (Figure 3a). The new monthly RF for May was generated from MODIS NDVI during 2012-2016, as shown in Figure 3b. For the example of 1 May, 15 days in April and 15 days in May (i.e., 15 days in the past and 14 days in the future) were given weights of 0.5 and 0.5 , respectively, in order to create the monthly average map in advance. Then, 
high-resolution NDVI data for the 30-day period from 2 April to 1 May 2017 were accumulated and the latest NDVI data were obtained (Figure 3c). This latest NDVI data for 1 May 2017 was applied to the look-up-table in Figure 2d and Equation (4). Finally, the latest reduction factor on 1 May 2017 was created (Figure 3d). Thus, this system created the most up-to-date NDVI maps on a daily basis and applied the resulting RFs to the ADAM2 model.

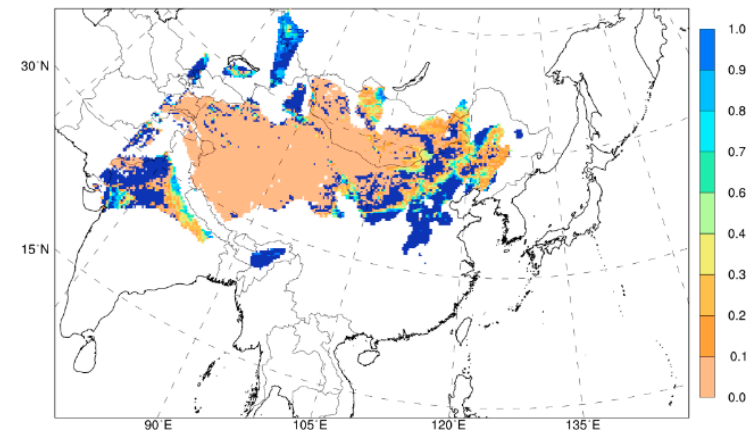

(a)

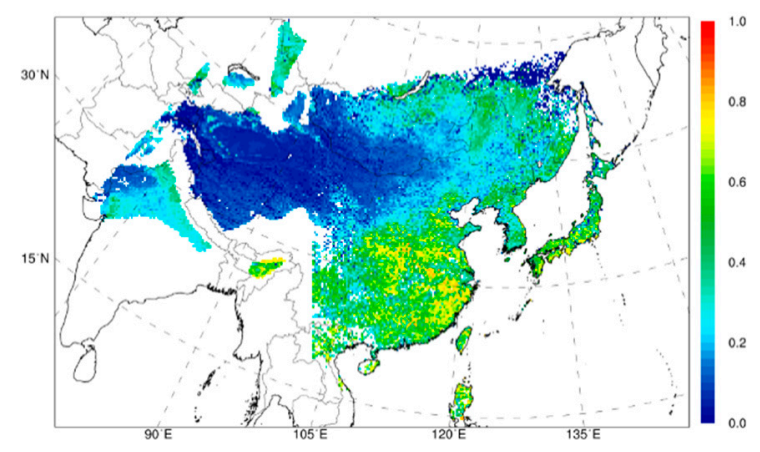

(c)

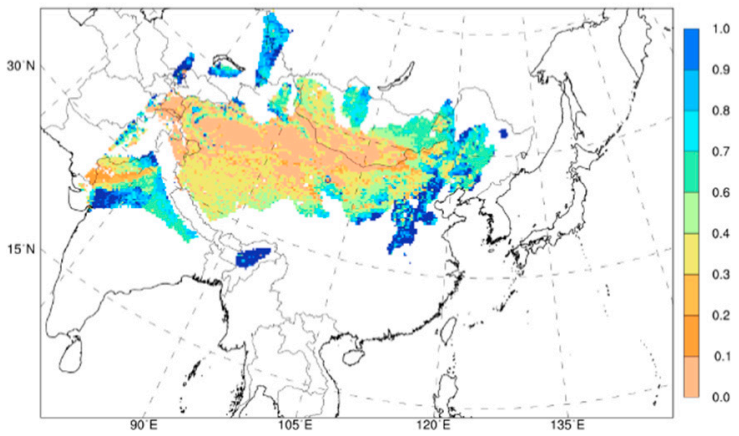

(b)

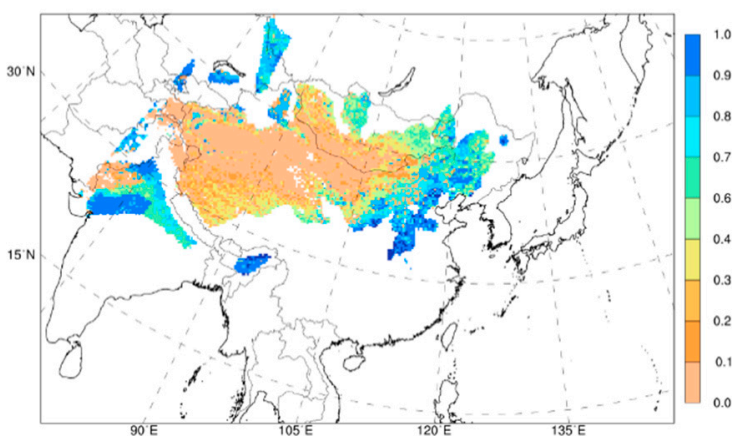

(d)

Figure 3. Spatial distribution of reduction factors retrieved from (a) average May Spot4 NDVI data for 2007-2012 and (b) average May MODIS NDVI data for 2012-2016. (c) Composite NDVI image for 1 May 2017 based on monthly averaged NDVI and most recent daily NDVI of the last 30 days. (d) Reduction factor distribution for 1 May 2017 retrieved using the latest NDVI image (Figure 3c) and new cumulative dust-rise occurrence probability function (CDF) (Figure 2d) for the dust source region of ADAM2.

\section{Validation of Results and Discussion}

To examine the impact of modifying the RF, experiments were performed between the current (CTL) and new (EXP) RFs calculated during the period from March to May, 2017, at 00 UTC (i.e., every $24 \mathrm{~h}$ ). The simulated data were compared with ground-based $\mathrm{PM}_{10}$ observation data from $27 \mathrm{KMA}$ sites, 15 CMA sites, 250 MOE sites in Korea, and 1498 MEE sites in China (Figure 4).

Figure 5 shows the $\mathrm{PM}_{10}$ comparison results for four representative sites (Yushe, Dandong, Seoul, and Busan) during March to May, 2017, whose locations are shown in Figure 4. Strong Asian dusts events occurred in Yushe and Dandong in mid-April and early May, as well as in Seoul and Busan, which are located in the downwind region. While both versions of ADAM2 (EXP and CTL) effectively simulate the $\mathrm{PM}_{10}$ observations related to these dust events, EXP simulations are closer to the observations than CTL simulations. In early May, when large Asian dusts occurred, the CTL over-simulates $\mathrm{PM}_{10}$ data in the source regions of Yushe and Dandong, whereas EXP simulations are again closer to the observations. Similar trends are obtained for Seoul and Busan, which is in good agreement with the root mean square error (RMSE). The RMSE values between CTL simulations and the observations in Yushe and Dandong source regions are 87.27 and 74.15, respectively, whereas those 
for EXP simulations are lower (79.37 and 47.63, respectively). Similarly, in Seoul and Busan in the downwind region, the RMSE values between CTL and observations are 57.72 and 40.0, respectively, whereas those for EXP are lower (31.64 and 27.21, respectively). Thus, the new version of ADAM2 (EXP) significantly reduces the RMSE of downwind dust emission simulations by $45 \%$ and $32 \%$, respectively.

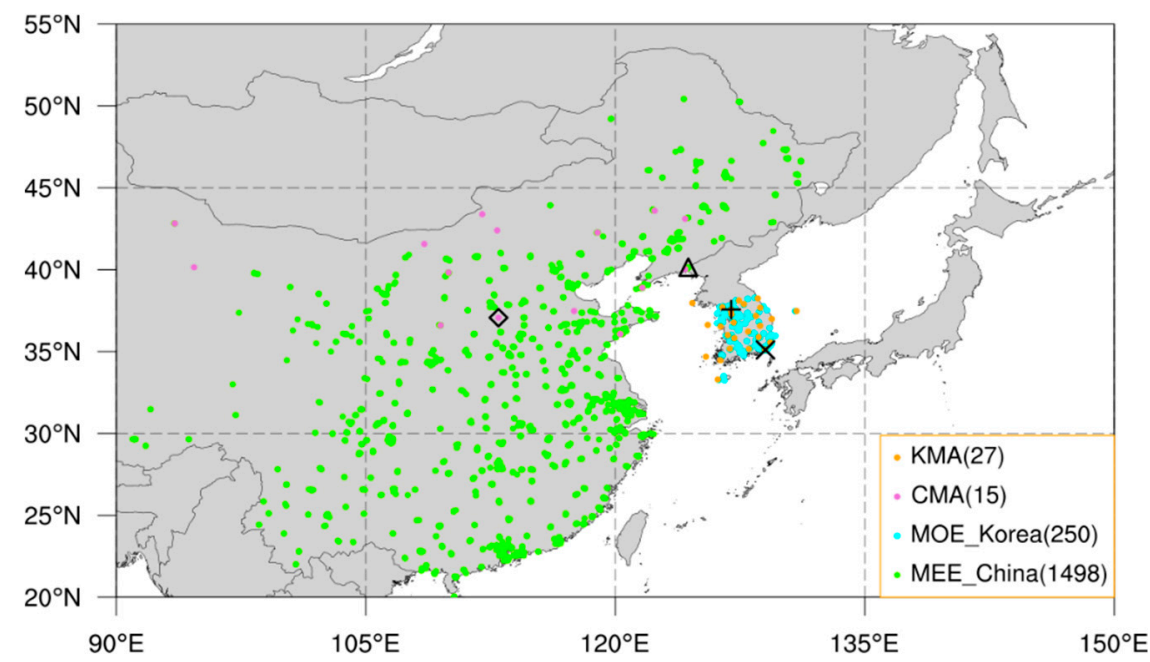

Figure 4. Spatial distribution of $\mathrm{PM}_{10}$ sites of Korea Meteorological Administration (KMA)(orange circles), China Meteorological Administration (CMA) (pink circles), Ministry of Environment of Korea (sky-blue circles), and Ministry of Ecology and Environment of China (green circles). Four representative sites of each $\mathrm{PM}_{10}$ network are also shown: Yushe (diamonds), Dandong (triangles), Seoul (plus symbols), and Busan (crosses).

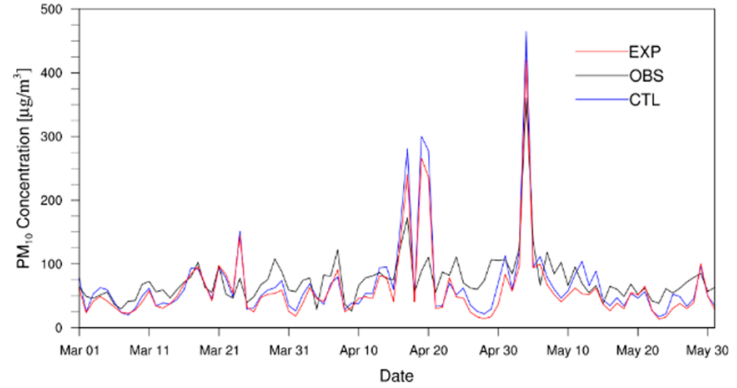

(a) Yushe CMA $\left(112.98^{\circ} \mathrm{E}, 37.07^{\circ} \mathrm{N}\right)$

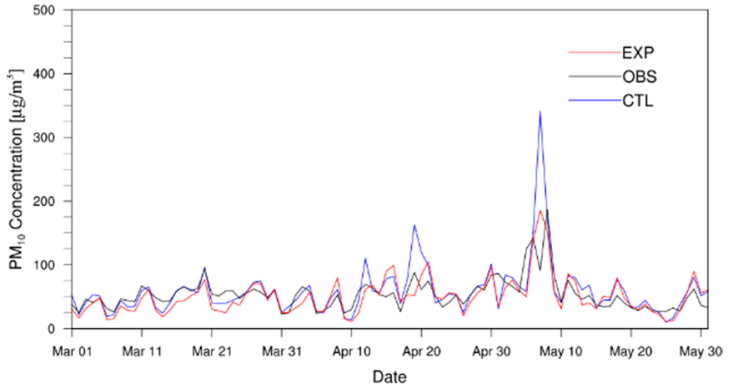

(c) Seoul KMA $\left(126.97^{\circ} \mathrm{E}, 37.57^{\circ} \mathrm{N}\right)$

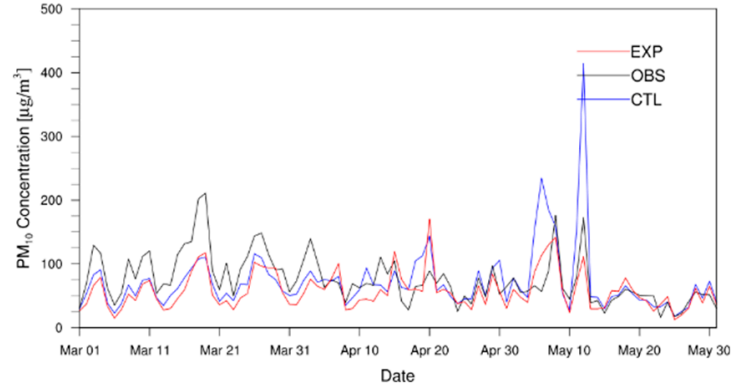

(b) Dandong MEE $\left(124.39^{\circ} \mathrm{E}, 40.15^{\circ} \mathrm{N}\right)$

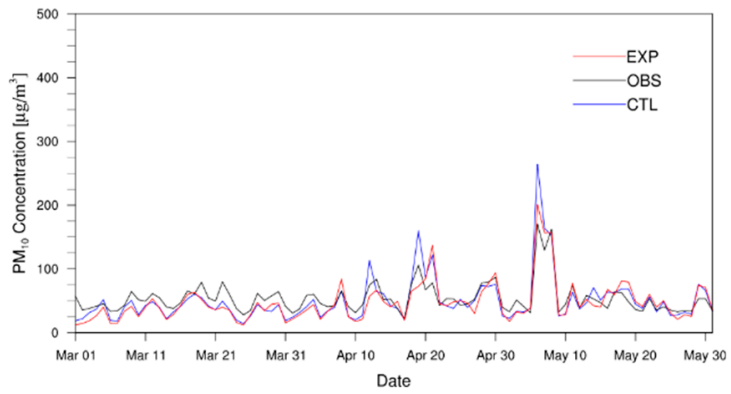

(d) Busan MOE $\left(129.03^{\circ} \mathrm{E}, 35.10^{\circ} \mathrm{N}\right)$

Figure 5. Time series of $\mathrm{PM}_{10} \mathrm{~s}$ observations (black line) and dust emissions simulated by ADAM2 (current version (CTL) (blue) and new version (EXP) (red)) at (a) Yushe, (b) Dandong, (c) Seoul, and (d) Busan sites during March to May, 2017.

The results of the RMSE analyses performed for all observation sites are shown in Table 2. In all regions, the RMSE is improved in the EXP version than the CTL version. Specifically, KMA 
RMSE values exhibit an improvement of approximately $24 \%$. The RMSE is more improved in Korea (KMA, MOE), which is located in the downwind region, than in China (CMA, MEE), which is close to the source region of Asian dust. The model results used in this comparison consider only $\mathrm{PM}_{10}$ for Asian dust; however, the observations include $\mathrm{PM}_{10}$ results not only for Asian dust but also for anthropogenic pollutants. Naturally, where there are more anthropogenic pollutants, the improvement rate (i.e., reduction ratio) of RMSE is relatively low. This explains the lower improvement rate of RMSE in China, where anthropogenic pollutant concentrations are higher than those in Korea. Overall, RMSE values are reduced by $11.58 \%$ when the RF is updated through the use of the latest MODIS NDVI data.

Table 2. Root mean square errors (RMSEs) of new (CTL) and existing (EXP) versions of ADAM2, as well as the difference and reduction ratio of RMSE values for observation sites across China (CMA and MEE) and Korea (KMA and MOE).

\begin{tabular}{cccccc}
\hline & KMA & CMA & MOE & MEE & All Sites \\
\hline RMSE (CTL) & 39.98 & 184.74 & 49.56 & 72.65 & 86.93 \\
RMSE (EXP) & 30.31 & 173.85 & 42.31 & 70.95 & 76.86 \\
$\begin{array}{c}\text { Difference of RMSE } \\
\text { (CTL-EXP) }\end{array}$ & 9.67 & 10.89 & 7.25 & 1.70 & 10.06 \\
$\begin{array}{c}\text { Reduction ratio of RMSE (\%) } \\
((\text { CTL-EXP)/CTL } \times \text { 100) }\end{array}$ & 24.18 & 5.90 & 14.63 & 2.34 & 11.58 \\
\hline
\end{tabular}

\section{Conclusions}

The ADAM2 Asian dust forecasting model has been operated by the KMA since 2010. In this study, we modified the dust emission reduction factor using updated NDVI data to reflect recent vegetation characteristics of the Asian dust source regions. To do that, we examined the cumulative dust-rise occurrence probability function (CDF) for each soil type over 12 months, using synoptic observations and MODIS NDVI data for a ten-year period, from 2007-2016. The dust emission reduction factor according to vegetation effects is parameterized with the CDF using the most up-to-date and high-resolution NDVI data with a horizontal resolution of $500 \mathrm{~m}$. This method has the advantage that continuous NDVI data can be used every day, whereas the previous version of ADAM2 involved the discontinuous application of NDVI on a monthly basis.

In order to compare the newly improved method with the existing ADAM2 version, we validated the model simulation results using ground $\mathrm{PM}_{10}$ observations for the spring of 2017. Accordingly, the updated reduction factor resulted in improved simulations in both Chinese and Korean observation sites, especially the downwind regions of Korea. This is thought to be due to the relatively large effects of anthropogenic pollutants in China, which resulted in relatively small improvements when using the new ADAM2 version. Overall, the RMSE was reduced by $11.58 \%$ by using the proposed method, indicating a significant improvement in the performance of the ADAM2 model due to employing the most recent NDVI daily data.

This study showed the importance of recent vegetation characteristics to the Asian dust prediction model. In future research, it will also be important to redefine the Asian dust source regions to reflect the most recent vegetation characteristics. In addition to analyzing the RMSE values of ground-based $\mathrm{PM}_{10}$ concentrations, it may also be valuable to analyze Asian dust days for further model evaluation [11].

Supplementary Materials: The following are available online at http://www.mdpi.com/2073-4433/10/11/702/s1, Figure S1: The cumulative dust-rise occurrence probability function (CDF) in the Gobi soil type region for each month. The red line indicates the CDF in Park et al. (2010), Figure S2: The same as Figure S1 except for the Sand soil type region, Figure S3: The same as Figure S1 except for the Loess soil type region, Figure S4: The same as Figure S1 except for the Mixed soil type region.

Author Contributions: S.-S.L. wrote the article; H.C.L. and S.-B.R. conceived and designed the experiments; Y.-K.L. and J.H.C. performed the validation analysis.

Funding: This work was funded by the Korea Meteorological Administration Research and Development Program “Development of Asian Dust and Haze Monitoring and Prediction Technology" under Grant (1365003013). 
Acknowledgments: The MODIS NDVI data product was retrieved from the online Data Pool, courtesy of the NASA Land Processes Distributed Active Archive Center (LP DAAC), USGS Earth Resources Observation and Science (EROS) Center, Sioux Falls, South Dakota at the following website: https://lpdaa.usgs.gov/tools/data-pool/.

Conflicts of Interest: The authors declare no conflict of interest.

\section{References}

1. Zhamsueva, G.S.; Zayakhanov, A.S.; Tsydypov, V.V.; Ayurzhanaev, A.A.; Dementeva, A.L.; Azzaya, D.; Oyunchimeg, D. Particularities of Formation and Transport of Arid aerosol in Central Asia. In Advanced Air Pollution; Nejadkoorki, F., Ed.; Intech: Rijeka, Croatia, 2011; pp. 51-66.

2. Giannadaki, D.; Pozzer, A.; Lelieveld, J. Modeled global effects of airborne desert dust on air quality and premature mortality. Atmos. Chem. Phys. 2014, 14, 957-968. [CrossRef]

3. Hong, Y.-C.; Pan, X.C.; Kim, S.Y.; Park, K.; Park, E.J.; Jin, X.; Yi, S.M.; Kim, Y.H.; Park, C.H.; Song, S.; et al. Asian dust storm and pulmonary function of school children in Seoul. Sci. Total Environ. 2010, 408, 754-759. [CrossRef] [PubMed]

4. Kashima, S.; Yorifuji, T.; Bae, S.; Honda, Y.; Lim, Y.H.; Hong, Y.C. Asian dust effect on cause-specific mortality in five cities across South Korea and Japan. Atmos. Environ. 2016, 128, 20-27. [CrossRef]

5. Kwon, H.J.; Cho, S.H.; Chun, Y.; Lagarde, F.; Pershagen, G. Effects of the Asian dust events on daily mortality in Seoul, Korea. Environ. Res. 2002, 90, 1-5. [CrossRef] [PubMed]

6. Zhang, X.; Zhao, L.; Tong, D.; Wu, G.; Dan, M.; Teng, B. A systematic review of global desert dust and associated human health effects. Atmosphere 2016, 7, 158. [CrossRef]

7. Lee, E.-H.; Sohn, B.J. Examining the impact of wind and surface vegetation on the Asian dust occurrence over three classified source regions. J. Geophys. Res. 2009, 114, D06205. [CrossRef]

8. Park, H.-S.; Sohn, B.J. Recent trends in changes of vegetation over East Asia coupled with temperature and rainfall variations. J. Geophys. Res. 2010, 115, D14. [CrossRef]

9. Lee, E.H.; Ha, J.C.; Lee, S.S.; Chun, Y. PM10 data assimilation over South Korea to Asian dust forecasting model with the optimal interpolation method. Asia Pac. J. Atmos. Sci. 2013, 49, 73-85. [CrossRef]

10. Lee, S.S.; Lee, E.H.; Sohn, B.J.; Lee, H.C.; Cho, J.H.; Ryoo, S.B. Improved dust forecast by assimilating MODIS IR-based nighttime AOT in the ADAM2 model. SOLA 2017, 13, 192-198. [CrossRef]

11. Hong, S.K.; Ryoo, S.B.; Kim, J.; Lee, S.S. Prediction of Asian dust days over Northern China using the KMA-ADAM2 model. Weather Forecast. 2018, 34, 1777-1787. [CrossRef]

12. Park, S.-U.; Choe, A.; Lee, E.H.; Park, M.S.; Song, X. The Asian Dust Aerosol Model 2 (ADAM2) with the use of Normalized Difference Vegetation Index (NDVI) obtained from the Spot4/vegetation data. Theor. Appl. Climatol. 2010, 101, 191-208. [CrossRef]

13. Kim, D.; Chin, M.; Bian, H.; Tan, Q.; Brown, M.E.; Zheng, T.; You, R.; Diehl, T.; Ginoux, P.; Kucsera, T. The effect of the dynamic surface bareness on dust source function, emission, and distribution. J. Geophys. Res. 2013, 118, 871-886. [CrossRef]

14. Huang, M.; Tong, D.; Lee, P.; Pan, L.; Tang, Y.; Stajner, I.; Pierce, R.B.; McQueen, J.; Wang, J. Toward enhanced capability for detecting and predicting dust events in the western United States: The Arizona case study. Atmos. Chem. Phys. 2015, 15, 12595-12610. [CrossRef]

15. Kim, D.; Chin, M.; Kemp, E.M.; Tao, Z.; Peters-Lidard, C.D.; Ginoux, P. Development of high-resolution dynamic dust source function-A case study with a strong dust storm in a regional model. Atmos. Environ. 2017, 159, 11-25. [CrossRef]

16. In, H.-J.; Park, S.-U. A simulation of long-range transport of Yellow Sand observed in April 1998 in Korea. Atmos. Environ. 2002, 4173-4187. [CrossRef]

17. Park, S.-U.; In, H.-J. Parameterization of dust emission for the simulation of the yellow sand (Asian dust) event observed in March 2002 in Korea. J. Geophys. Res. 2003, 108, 4618. [CrossRef]

18. Byun, D.; Schere, K.L. Review of the governing equations, computational algorithms, and other components of the Models-3 Community Multiscale Air Quality (CMAQ) modeling system. Appl. Mech. Rev. 2006, 59, 51-77. [CrossRef]

19. Davies, T.; Cullen, M.J.; Malcolm, A.J.; Mawson, M.H.; Staniforth, A.; White, A.A.; Wood, N. A new dynamical core for the Met Office's global and regional modelling of the atmosphere. Q. J. R. Meteorol. Soc. 2005, 131, 1759-1782. [CrossRef] 
20. Park, S.; Kim, D.-J.; Lee, S.-W.; Lee, K.-W.; Kim, J.; Song, E.-J.; Seo, K.-H. Comparison of extended medium-range forecast skill between KMA ensemble, ocean coupled ensemble, and GloSea5. Asia-Pac. J. Atmos. Sci. 2017, 53, 393-401. [CrossRef]

21. Gillette, G.A. Production of dust that may be carried to great distance. In Desert Dust: Origin, Characteristics, and Effect on Man; Special Paper; Geological Society of America: Boulder, CO, USA, 1981; Volume 186, pp. 11-26.

22. Westphal, D.L.; Toon, O.B.; Carson, T.N. A two-dimensional investigation of the dynamics and microphysics of Saharan dust storms. J. Geophys. Res. 1987, 92, 3027-3049. [CrossRef]

23. Park, S.U.; Lee, E.H. Parameterization of Asian dust (Hwangsa) particle-size distributions for use in dust emission models. Atmos. Environ. 2004, 38, 2155-2162. [CrossRef]

24. Wesely, M.L.; Hicks, B.B. Some factors that affect the deposition rates of sulfur dioxide and similar gases on vegetation. J. Air Pollut. Control Assoc. 1977, 27, 1110-1116. [CrossRef]

25. Wesely, M.L. Parameterization of surface resistances to gaseous dry deposition in regional-scale numerical models. Atmos. Environ. 1989, 23, 1293-1304. [CrossRef]

26. Dennis, R.; Mchenry, J.; Barchet, W.; Binkowski, F.; Byun, D. Correcting RADM's sulfate underprediction: Discovery and correction of model errors and testing the corrections through comparisons against field data. Atmos. Environ. 1993, 27, 975-997. [CrossRef]

27. Walcek, C.; Taylor, G.R. Theoretical method for computing vertical distributions of acidity and sulfate production within cumulus clouds. J. Atmos. Sci. 1986, 43, 339-355. [CrossRef]

28. Chang, J.S.; Brost, R.A.; Isaksen, I.S.A.; Madronich, S.; Middleton, P.; Stockwell, W.R.; Walcek, C.J. A three-dimensional Eulerian acid deposition model: Physical concepts and formulation. J. Geophys. Res. 1987, 92, 14681-14700. [CrossRef]

29. Didan, K. MYD13C2 MODIS/Aqua Vegetation Indices Monthly L3 Global 0.05Deg CMG V006; NASA EOSDIS Land Processes DAAC: Sioux Falls, SD, USA, 2015. [CrossRef]

30. Yi, H. The Soil Atlas of China; Cartographic Publishing House: Beijing, China, 1986; pp. 1-12.

31. Scheftic, W.; Zeng, X.; Broxton, P.; Brunke, M. Intercomparison of Seven NDVI Products over the United States and Mexico. Remote Sens. 2014, 6, 1057-1084. [CrossRef] 